\title{
Sports, in association with specific exercises, can help to achieve better results in controlling the evolution of scoliosis
}

\author{
M Romano ${ }^{1 *}$, S Negrini ${ }^{2,3}$ \\ From 9th International Conference on Conservative Management of Spinal Deformities - SOSORT 2012 \\ Annual Meeting \\ Milan, Italy. 10-12 May 2012
}

\section{Background}

SOSORT Guidelines recommend that patients, who follow a conservative treatment program for scoliosis, practice sport activities in association with Specific Physiotherapy Exercises (PSE). From a theoretical point of view, the sport activity combines well with the goals of treatment of a disease characterized by a postural dysfunction.

\section{Aim}

The purpose of this study is to compare the results at the end of rapid growth spurt (Risser 3), between a group of patients treated with a conservative protocol (exercise and/or brace), and a group of patients who have added some sport activity to the same protocol.

\section{Methods}

We evaluated 543 patients (497 females/45 males) treated for idiopathic scoliosis with either PSE only (144 patients, $\left.15.5^{\circ} \pm 9.3^{\circ} \mathrm{Cobb}\right)$, or brace and PSE (399 patients, $\left.33.3^{\circ} \pm 12.1^{\circ}\right)$. Patients started treatment at Risser $0-1$, with a minimum age of 10 years, and were followed up to Risser 3. A comparison was then made between the following subgroups:

PSE + Sport (PSESP: 88 patients, $14.8^{\circ} \pm 5.7^{\circ}$ ) vs PSE only (PSE: 56 patients, $16.6^{\circ} \pm 13.1^{\circ}$ )

Brace + PSE + sport (BPSESP: 182 patients, $32.2^{\circ} \pm 10.7^{\circ}$ ) vs Brace + PSE (BPSE: 217 patients, $34.2^{\circ} \pm 13.2^{\circ}$ ) Outcome: Variation of ${ }^{\circ} \mathrm{Cobb}$ at Risser 3 Statistical analysis: ANOVA, T-Test.

\section{Results}

At the onset we did not find statistically significant differences between the groups. The comparison of ${ }^{\circ} \mathrm{Cobb}$ at Risser 1, and 3, shows better results in PSESP (improvement of $0.53^{\circ}$ ) compared to PSE (progression of $\left.1.75^{\circ}\right)$, but the difference is not statistically significant. Analysis of the results of braced patients at Risser 3 showed improvement of both groups (BPSESP $3.87^{\circ}$, BPSE $\left.3.01^{\circ}\right)$. The difference for the final result was statistically significant $(\mathrm{P}=0.04)$.

\section{Conclusions}

In the context of conservative treatment, sport activity, in association with a specific exercise program, seems to be useful to contrast the evolution of scoliosis, especially for braced patients.

\section{Author details}

${ }^{1}$ ISICO (Italian Scientific Spine Institute) Milan, Italy. ${ }^{2}$ University of Brescia, Brescia, Italy. ${ }^{3}$ RCCS Don Gnocchi, Milan, Italy.

Published: 3 June 2013

\section{References}

1. Kenanidis E, Potoupnis ME, Papavasiliou KA, Sayegh FE, Kapetanos GA: Adolescent idiopathic scoliosis and exercising: is there truly a liaison? Spine 2008, 33(20):2160-2165.

2. Meyer C, Haumont T, Gauchard GC, Leheup B, Lascombes P, Perrin PP: The practice of physical and sporting activity in teenagers with idiopathic scoliosis is related to the curve type. Scand J Med Sci Sports 2008, 18(6):751-755.

\section{doi:10.1186/1748-7161-8-S1-019}

Cite this article as: Romano and Negrini: Sports, in association with specific exercises, can help to achieve better results in controlling the evolution of scoliosis. Scoliosis 2013 8(Suppl 1):019.

${ }^{1}$ ISICO (Italian Scientific Spine Institute) Milan, Italy

Full list of author information is available at the end of the article

(C) 2013 Romano and Negrini; licensee BioMed Central Ltd. This is an Open Access article distributed under the terms of the Creative 